\title{
BAŞLANGIÇ OKLUZAL ÇÜRÜKLERE UYGULANAN İKİ FARKLI NANO KOMPOZİTİN İKI YILLIK KLİNİK PERFORMANSI
}

\section{CLINICAL PERFORMANCE OF TWO DIFFERENT NANO COMPOSITES IN INITIAL OCCLUSAL CARIES : TWO YEARS RESULTS}

\section{Dr. Dt. Aslı BERBER}

Prof. Dr. Meserret BAŞEREN**
Makale Kodu/Article code: 4984

Makale Gönderilme tarihi: 30.04 .2021

Kabul Tarihi: 26.08.2021

DOI : $10.17567 /$ ataunidfd.990083
Aslı Berber: ORCID ID: 0000-0001-6848-5700

Meserret Başeren : ORCID ID: 0000-0003-3537-8567

öz

Amaç: Bu çalışmada; başlangıç okluzal çürüklerin tedavisinde kullanılan nanokompozitlerin 2 yıllık klinik performanslarının değerlendirilmesi amaçlanmıştır.

Materyal ve Metod: Araştırmaya katılan bireyler, Hacettepe Üniversitesi Diş Hekimliği Fakültesi Restoratif Diş Tedavisi Kliniğine başvuran, en az 2 adet başlangıç okluzal çürüğü bulunan hastalar arasından seçildi (yaş aralığı 18-30). Restore edilecek dişler görsel muayene yöntemi ile değerlendirildi. Radyografilerin incelenmesinden sonra DIAGNodent pen ile ölçümler yapıldı. Dişlere; minimal invaziv okluzal kavite preparasyonu yapıldıktan sonra kondanse edilebilen bir nanokompozit (Quixfil, Dentsply) ve akışkan nanokompozit (SureFil SDR Flow, Dentsply) üretici firmanın önerileri doğrultusunda uygulandı. Çalışmaya katılan 23 'ü kadın 20'si erkek olmak üzere 43 gönüllü bireye 356 adet restorasyon yapıldı. Kompozit restorasyonlar, başlangıç, 6., 12., 18., 24. aylarda modifiye USPHS kriterlerine göre değerlendirildi. İstatistiksel değerlendirme için "Pearson Chi-square", "Fisher Exact" ve "Cochran $\mathrm{Q}$ " testleri kullanıldı $(\mathrm{p}<0.05)$.

Bulgular: 24 ay sonunda 38 hastada 316 adet restorasyon değerlendirildi. Tüm modifiye USPHS kriterleri için restorasyon grupları arasında istatistiksel olarak anlamlı fark bulunmadı $(p>0.05)$. Her grubun kendi içinde, kenar uyumu, kenar renklenmesi, anatomik form ve hassasiyet kriterlerinin zaman içindeki değişimi anlamlıyken $(p<0.001)$; retansiyon, renk uyumu, sekonder çürük, yüzey yapısı, kriterlerinin değişimi anlamlı bulunmadı $(p>0.05)$

Sonuç: Bu çalş̧mada her iki rezin kompozitin başlangıç okluzal çürüklerin tedavisinde klinik olarak kabul edilebilir bir performans gösterdiği sonucuna varılmıştır.

Anahtar kelimeler: Nanokompozit, Başlangıç Okluzal Çürük, Klinik Performans, Dıagnodent Pen.

\section{ABSTRACT}

Aim: The purpose of this study was to evaluate the two-year clinical performance of one condansable nano composite and one flowable nanocomposite in minimal occlusal cavities.

Material and methods: Patients were selected from who visiting the Hacettepe University School of Dentistry Department of Restorative Dentistry for the teratment of occlusal caries (age range 18-30 years). At the beginning of treatment, teeth were diagnosed by visual inspection with a mirror and lesions were evaluated with periapical and bitewing radiographs. After that to achieve standardization measurements were made with the DIAGNOdent Pen. 20 male and 23 female subjects participated to study. A total of 356 occlusal cavities were restored with condansable nano composite (Quixfil, Dentsply) and flowable nano composite (SureFil SDR Flow, Dentsply) according to manufacturers' instructions. All restorations were placed by one operator. The restorations were evaluated clinically within 1 week after placement and after 6., 12., 18., 24. months using modified USPHS criteria by one examiner. Statistical analysis was completed using Pearson Chi-square, Fisher- Exact and Cochran Q tests $(\mathrm{p}<0,05)$.

Results: At the end of 24 months; in 38 patients 316 restorations were evaluated. No statistically significant differences were found between two resin composites $(p>0.05)$. There were significant differences between time zones with each restoration group for marginal adaptaion, marginal discoloration, anatomic form, post operative sensitivity $(p<0.001)$. Interms of Retantion, color match, seconder caries, surface texture no significant differences have been found in each restorative materials groups $(p>0,05)$.

Conclusion: It was concluded that; different types of resin composites demonstrated acceptable clinical performance in initial occlusal caries.

Keywords: Nanocomposite, İnitial Occlusal Caries, Clinical Performance, Diagnodent Pen.

\footnotetext{
${ }^{*}$ Gölcük Ağız ve Diş Sağlı̆̆ı Merkezi

${ }^{* *}$ Hacettepe Üniversitesi Diș Hekimliği Fakültesi Restoratif Diș Tedavisi Bilim Dalı
}

Kaynakça Bilgisi: Berber A, Başeren M. Başlangıç okluzal çürüklere uygulanan iki farklı nano kompozitin iki yıllık klinik performansı. Atatürk Üniv Diş Hek Fak Derg 2021; 31: 547-55.

Citation Information: Berber A, Baseren M.. Clinical performance of two different nano composites in Initial occlusal caries : two years results. J Dent Fac Atatürk Uni 2021; 31: 547-55. 


\section{GİRIş}

Diş çürüğü; dişin yapısı, ağızda bulunan mikroorganizmalar, tükürüğün bileşimi, bakteri plağı ve beslenme alışkanlığı gibi bir dizi faktörün etkileşimi sonucu oluşan bir hastalıktır. ${ }^{1}$

Son yıllarda diş hekimliği alanındaki gelişmelere paralel olarak; çürükle ilgili daha ayrıntılı bilgi sahibi olunması sonucu ailelerin eğitilmesi, beslenme alışkanIıklarının düzenlenmesi, fırçalama alışkanlığının kazanılması ve florür kullanımı ile diş çürüğünden korunmak için birçok yöntem geliştirilmiştir. ${ }^{1,2} \mathrm{Bu}$ koruyucu yöntemler planlı bir şekilde uygulandığı takdirde çürük oranında önemli azalmalar görülmektedir. ${ }^{1.2}$ Florürlerin kullanımlarındaki artışa bağlı olarak çürüğün ilerleme hızı yavaşlamış ancak "gizli çürük" denen yeni bir durum ortaya çıkarmıştır. Gizli çürük, klinik olarak hatalı tanı koyulabilen, sağlam diş dokusu ile örtülü çürük lezyonlarını tanımlamaktadır. Florür, demineralizasyon sonrasında meydana gelen kavitasyona karşı minenin daha dirençli olmasını sağlar. Ancak mineral iyonlarının yüzey altı bölgesine difüzyonunu engelleyerek okluzal çürük lezyonlarının görsel muayenede teşhis edilememe sine neden olur. Bu durumda durmuş ya da kavitasyon oluşmuş lezyonlar restore edilebilirken, başlangıç okluzal lezyonlar restore edilmeden bırakılabilir. 2,3

Tedavi planlamasında erken teşhis günümüz diş hekimliğinde oldukça önemli bir yer tutmaktadır. Bu amaçla genellikle, görsel inceleme ve radyograflar kullanılır. Ancak birçok çürük teşhis yöntemi de mevcuttur. Bunlardan birisi de geleneksel yöntemlerin eksik yönlerini giderebilmek amacıyla üretilen, mineral kaybının görüldüğü bölgelerin optik özelliklerinin sağlam dokudan farklı olması özelliğinden yola çıkılarak geliştirilen lazer floresans esasına dayalı calışan DIAGNOdent'tir. ${ }^{3,4}$ İncelenen bölgeye zarar vermemesi, x-ışını kullanmaması, çürük derinliğini numerik değerlerle ifade ederek göreceliliği ortadan kaldırabilmesi önemli avantajlarıdır. ${ }^{4}$

Günümüz teknolojisindeki gelişmelerin; hastalıkların erken dönemde teşhis edilmesine imkan vermesi, diş çürüğünün tedavi planlamasında da önemli değişikliklere neden olmuştur. Böylece extension for prevention (korumak için genişletmek) görüşü yerini koruyucu yöntemlere ve minimal invaziv tedaviye bırakmıştır. Bu amaçla diş hekimliğinde çok çeşitli restorasyon materyali (amalgam, kompozit, cam iyonomer gibi) bulunmaktadır. Bu materyaller arasında arka grup dişlerde en çok amalgam kullanılmaktadır. ${ }^{4,5}$ Amalgam, uygu- laması kolay, ekonomik ve çiğneme basınçlarına karşı dayanıklı bir restoratif materyaldir. Ancak yüksek ISı geçirgenliği, cıva içermesi, korozyona uğrayarak renklenme oluşturması ve estetik olmaması gibi dezavantajlara sahiptir. ${ }^{5}$

Son yıllarda minimal invaziv yaklaşımların güncel hale gelmesi ile daha az diş dokusunun uzaklaştırılmasına olanak sağladığı ve estetik olarak tatmin edici sonuçlar elde edildiği için nano kompozitlerin kullanımı popüler hale gelmiştir. Estetik gereksinimi karşılamak amacıyla daha çok ön dişlerde kullanılmalarına rağmen geliştirilen mekanik özellikleri sayesinde artık arka grup dişlerde de sıklıkla kullanılmaktadırlar. ${ }^{4-6}$ Restoratif materyal seçeneğinin fazla olması diş hekimlerini çoğu kez kararsızlığa düşürmektedir. Böylece materyallerin yapıları ve kullanımları hakkında daha ayrıntılı bilgi sahibi olma gereğini doğurmuştur. Bu nedenle kompozit rezinlerin fiziksel ve mekanik özellikleri ile ilgili çok sayıda in vitro çalışma yapılmaktadır. Ancak ağız ortamında materyallerin çeşitli özelliklerini etkileyebilecek pek çok faktör bulunduğu için in vitro çalışmalarda materyalin klinik başarısı hakkında net bir bilgi elde edilememektedir.Bu nedenle klinik takip çalışmalarının sonuçları restoratif materyallerin performanslarının belirlenmesinde daha etkili kanıt niteliği taşımaktadır. ${ }^{6-8}$

Başlangıç okluzal çürüklerin tedavisinde kullanılan akışkan kompozitlerin klinik takibinin yapıldığı az sayıda çalışma vardır.9,10 $\mathrm{Bu}$ nedenle çalışmamızda, başlangıç okluzal çürüklerin tedavisinde uygulanan kondanse edilebilen nano kompozit ile akışkan nano kompozitin 2 yıllık klinik performansının değerlendirilmesi amaçlanmıştır. Tüm bu bilgiler ışığında çalışmamızın hipotezini akışkan nano kompozitin klinik performansının ile kondanse edilebilen kompozitin klinik performansı ile aynıdır şeklinde oluşturduk.

\section{MATERYAL VE METOD}

Bu çalışma Hacettepe Üniversitesi Diş Hekimliği Fakültesi Restoratif Diş Tedavisi Anabilim Dalı'nda yürütüldü. Araştırma için Hacettepe Üniversitesi Tıbbi, Cerrahi ve ilaç Araştırmaları Etik Kurulu'ndan 03.02.2011 tarihli HEK 11/16-5 sayılı etik kurul onayı alındı. (ek 1)

Yaşları 18-30 arasında değişen 43 gönüllü birey (20 erkek-23 kadın) araştırma ile ilgili ayrıntılı olarak bilgilendirildi ve katılımları için yazılı onayları alındı. (ek2)

Çalışma kapsamına alınan bireyler 01.12.2010 01.02.2011 tarihleri arasında Hacettepe Üniversitesi Diş Hekimliği Fakültesi Restoratif Diş Tedavisi'ne baş- 
vuran hastalar arasından seçildi. Araştırmaya herhangi bir sistemik hastalığı olmayan, oral hijyeni iyi, ağzında en az 2 adet başlangıç düzeyde okluzal çürüğü bulunan hastalar alındı. Ağız kuruluğu ve periodontal hastalığı bulunan, bruksizmi olan, kontrol randevularına gelmeyi kabul etmeyen, uzun süreli antienflamatuar kullanımı gerektiren psikiyatrik ya da sistemik rahatsızlığa sahip olan, hamile ya da emzirme dönemindeki bireyler çalışmaya dahil edilmedi.

Çalışmaya dahil edilen dişlerin ortak özellikleri ise şu şekilde belirlendi: Okluzal yüzey dışında hiçbir bölgede çürük bulunmaması, daha önceden yapılmış herhangi bir restorasyon ya da fissür örtücü bulunmaması, dişin kendisinde ya da periapikal dokularda herhangi bir patoloji varlığı olmaması. Çalışmaya katılan bireylerin cinsiyet dağılımı ve okluzal çürük bulunan dişlerin dağıımı tablo 1'de gösterilmektedir.

Tablo 1. Çalışmaya Katılan Dişlerin Dağılımı

\begin{tabular}{|l|l|}
\hline Skorlar & \multicolumn{1}{|c|}{ Görsel Muayene Kriterleri } \\
\hline 0 & Dişin hava ile kurutulması sonucunda minenin sağlıklı görür \\
\hline 1 & Diş kurutulduktan sonra hafif bir opasite ya da renklenme \\
\hline 2 & Diş kurutulmadan nemliyken de opasite ya da renklenme \\
\hline 3 & $\begin{array}{l}\text { Mine tabakasının altındaki dentin tabakasından yansıyan gri } \\
\text { renklenme }\end{array}$ \\
\hline
\end{tabular}

Tüm dişler; görsel olarak muayene edildi. Muayene sonucunda fissür çürüğü var olduğu düşünülen dişlerin radyografileri çekildi ve incelendi. Daha sonra da DIAGNOdent Pen (DD2091, KaVo, Biberach, Almanya) ile okluzal yüzeyden çürük değerlendirme ölçümleri yapıldı.

Görsel değerlendirme sırasında sadece hava spreyi ve reflektör ışığı kullanıldı. Sond kullanılarak herhangi bir değerlendirme yapılmadı. Tablo 2'de gösterilen görsel değerlendirme kriterleri kullanılarak; 1 ve 2 ile skorlanan dişler çalışmaya dahil edildi. ${ }^{11}$

Tablo 2. Görsel muayene kriterleri

\begin{tabular}{|l|c|c|c|c|c|}
\hline \multirow{2}{*}{ Cinsiyet } & \multicolumn{2}{|c|}{ Üst Çene } & \multicolumn{2}{c|}{ Alt Çene } & \multirow{2}{*}{ Toplam } \\
\cline { 2 - 5 } & Premolar & Molar & Premolar & Molar & \\
\hline Kadın (20) & 10 & 0 & 7 & 2 & 199 \\
\hline Erkek (23) & 7 & 4 & 6 & 70 & 157 \\
\hline Toplam & 17 & 64 & 13 & 162 & 356 \\
\hline
\end{tabular}

Görsel muayenesinde çürük varlığı tespit edilen dişlerin bite-wing ve periapikal radyografileri incelendi. Tablo 3'de gösterilen radyografik muyene kriterleri göz ününe alınarak 3 ve üzeri ile skorlanan dişler çalışma dışı bırakıldı. ${ }^{11}$ Başlangıç okluzal çürüklerin 1 ve 2 ile skorlanan düzeyde görüntü vermesi ve teşhis edilmesi zor olduğu radyografide dentin ve derin dentin çürüğü olan dişler çalışmaya dahil edilmedi.

Tablo 3. Radyografik muayene kriterleri

\begin{tabular}{|l|l|}
\hline Skorlar & Radyografik Muayene Kriterleri \\
\hline 0 & Radyolüsensi yok \\
\hline 1 & Minede radyolüsensi var \\
\hline 2 & Mine dentin sınııında radyolüsensi var \\
\hline 3 & Dentinde radyolüsensi var \\
\hline
\end{tabular}

DIAGNOdent Pen ölçümleri için DIAGNOdent Pen 2190 cihazı kullanıldı. Uygulama için önce cihaz kalibrsayonu üretici firmanın önerileri doğrultusunda yapıldıktan sonra her hastada bir dişin okluzal ölçümü yapılmadan önce ağız içindeki sağlam dişle ile de kalibrasyon sağlandı. Her diş için yaklaşık 10 saniye süre ile 3 defa ölçüm yapıldı ve en yüksek değer skor olarak kaydedildi. Tablo 4'de gösterilen DIAGNodent Pen ölçüm kriterleri kullanılarak; D1ve D2 ile skorlanan yani mine çürüğü ya da başlangıç dentin çürüğüne sahip olan dişler çalışmaya dahil edildi. ${ }^{11,12}$

Tablo 4. DIAGNodent Pen ölçüm kriterleri

\begin{tabular}{|l|c|ll|}
\hline Ölçüm Değerleri & Skorlar & Ölçüm Kriterleri & \\
\hline $0-13$ & D0 & Sağlıkıı Diş Dokusu & \\
\hline $14-20$ & D1 & $\begin{array}{l}\text { Demineralizasyon Başlangıcı } \\
\text { Çürük) }\end{array}$ & (Minede \\
\hline $21-29$ & D2 & $\begin{array}{l}\text { Demineralizasyon } \\
\text { Ulaşmış) }\end{array}$ & (Çürük Dentine \\
\hline 30 ve YukarıSı & D3 & Derin Dentin Çürüğü & \\
\hline
\end{tabular}

Çalışmaya dahil edilen başlangıç okluzal çürüğe sahip dişlere; nanofil dolduruculu kondanse edilebilen hibrit rezin kompozit ve nanofil dolduruculu akışkan rezin kompozit uyguland.

Uygulamaya hangi dişten başlanacağına yazı tura atılarak rastgele karar verildi. Daha sonra saat yönü esas alınıp, diğer tüm restorasyonlar tamamlandı.

Restore edilecek dişlere; hızlı turla dönen aerator ile su soğutması altında minimal invaziv kavite preperasyonu yapıldı. Kavite kenarlarına bizotaj yapılmadı. Gereksiz doku kaldırmaktan kaçınıldı. Çürük yavaş turla dönen mikromotorla su soğutması altında çelik rond frez ile temizlendi. Kavite preparasyonundan sonra kavite derinliği ve boyutları tekrar değerlendirildi. Kavite tabanının minede ya da dentinde olduğu not edildi.

Kavite tabanı minede ise $30 \mathrm{sn}$, dentinde ise mineye 30, dentine 15 sn olacak şekilde \%37'lik fosforik asit (Ivoclar Vivadent-Elwangen-Almanya) uygulandı. Daha sonra 15 sn su ile yıkanarak kaviteler temizlendi. Tabanı dentini içeren kavitelerde hafif 
nemli kalmasını sağlamak amacıyla kavite içerisine bir pamuk yerleştirilerek hava su spreyi ile kurutma yapıldı. Kavite tabanı minede olan preperasyonlarda ise normal kurutuldu. Prime\&Bond NT (DentsplyKonstanz-Almanya) fırça yardımıyla, asit ile pürüzlendirilmiş mine ve dentin yüzeyine sürüldü, 15 sn beklenerek, 5 sn hava ile inceltildi. LED ışık kaynağı (SDI Dental-Köln-Almanya) ile 10 sn polimerize edildi. Surefil SDR Flow tek tabaka halinde kaviteye yerleştirildi. 40 sn LED ışık kaynağı ile polimerize edildi. Quixfil Posterior, kavitenin derinliğine bağlı olarak oblik tabakalama tekniği ile kaviteye yerleştirildi, LED ışık kaynağı ile 40 sn polimerize edildi.

Bitirme ve polisaj işlemleri ISı oluşumunu engellemek için mikro motorla su altında yapıldı. Restorasyonların bitirme işleminde elmas bitirme frezleri kullanıldı. Bitirme frezleri dişin okluzal yüzey anatomisine uygun şekilde tutularak, fazla restoratif materyal dişten uzaklaştırıldı. Artikülasyon kağıdı ile yükseklik kontrol edildi. Polisaj aşamasında; Sof-lex (3M ESPESt.Paul-Amerika) aluminyum oksit emdirilmiş disk seti kullanıldı.

Çalışmada her iki restoratif materyal için aynı (A2) renk kullanıldı. Dişlerin izolasyonu rulo pamuklarla sağlandı. Tüm dişler tek bir hekim tarafından restore edildi. Restoratif materyaller üretici firmaların önerileri doğrultusunda uygulandı. Kullanılan restoratif materyallerin dişlere göre dağılımı ve örnek grupları tablo 5 'te gösterilmektedir. Toplam 356 adet restorasyon 2 aylık süre içerisinde yapıldı. Çalışmada kullanılan materyallerin ticari adları, üretici firmaları, kimyasal içerikleri ise tablo 6'da gösterilmektedir.

\section{Restorasyonların Değerlendirilmesi}

Restorasyonlar, uygulandıktan bir hafta sonra (başlangıç), 6., 12., 18. ve 24. aylarda, tedaviyi uygulayan hekimden farklı başka bir araştırmacı tarafından modifiye USPHS kriterlerine (tablo 7) göre değerlendirildi. ${ }^{13,14}$ Değerlendirme sonuçları kişisel bilgi ve değerlendirme formlarına kaydedildi (Ek 3).

\section{Ístatistiksel Değerlendirme}

Restorasyonların klinik olarak değerlendirme sonucunda elde edilen verilerinin analizinde; her zaman diliminde restorasyon grupları arasında fark olup olmadığı "Pearson Chi -Square" ve "Fisher Exact" testleri ile analiz edildi. Her restorasyon grubunun kendi içinde zamana bağlı değişimi arasındaki farkın anlamlılığı için "Cochran Q" testi kullanıldı.
Tablo 5. Restoratif materyallerin dişlere göre dağılımı

\begin{tabular}{|c|c|c|c|c|c|}
\hline \multirow{2}{*}{ Materyal } & \multicolumn{2}{|l|}{ Üst Çene } & \multicolumn{2}{|l|}{ Alt Çene } & \multirow[t]{2}{*}{ Toplam } \\
\hline & Premolar & Molar & Premolar & Molar & \\
\hline $\begin{array}{l}\text { Grup } 1 \\
\text { Quixfill Posterior }\end{array}$ & 9 & 82 & 6 & 79 & 178 \\
\hline $\begin{array}{l}\text { Grup } 2 \\
\text { Surefill SDR Flow }\end{array}$ & 8 & 81 & 7 & 82 & 178 \\
\hline Toplam & 17 & 163 & 13 & 163 & 356 \\
\hline
\end{tabular}

Tablo 6. Çalışmada kullanılan restoratif materyallerin içerikleri

\begin{tabular}{|c|c|c|c|c|}
\hline Materyal & $\begin{array}{l}\text { Üretici } \\
\text { Firma }\end{array}$ & Kimyasal İçeriği & $\begin{array}{c}\text { Doldurucu } \\
\text { Partikül } \\
\text { İçeriği } \\
\text { (Ağırlık) }\end{array}$ & Seri No \\
\hline $\begin{array}{l}\text { Surefil } \\
\text { SDR } \\
\text { Flow } \\
\text { (Akışkan } \\
\text { kompozit } \\
\text { rezin) }\end{array}$ & $\begin{array}{l}\text { Dentsply } \\
\text { Konstan } \\
\text { Almanya }\end{array}$ & $\begin{array}{c}\text { Baryum-alumino-floro-borosilikat } \\
\text { cam,stronsiyum-alumino-fluoro- } \\
\text { silikat cam, modifiye üretan } \\
\text { dimetakrilat rezin, etoksilat bisfeno } \\
\text { A dimetakrilat (EBPADMA), } \\
\text { trietilenglikol dimetakrilat } \\
\text { (TEGDMA), kamforokinon } \\
\text { (CQ),fotoinitiatör, fotoakselatör, } \\
\text { buti hidroksil tolun (BHT), UV } \\
\text { stabilizatör, titanyumdioksit, demir } \\
\text { oksit pigment, floresans ajan. }\end{array}$ & $\% 68$ & 091209 \\
\hline $\begin{array}{l}\text { Quixfil } \\
\text { Posterior } \\
\text { (Kondanse } \\
\text { edilebilir } \\
\text { kompoizt } \\
\text { rezin) }\end{array}$ & $\begin{array}{l}\text { Dentsply } \\
\text { Konstan } \\
\text { Almanya }\end{array}$ & $\begin{array}{l}\text { UDMA, TEGDMA, di ve trimetakrila } \\
\text { rezinler, karboksilit asit midifiye } \\
\text { trimetakrilat rezin, kamforokinon } \\
\text { (CQ),fotoinitiatör, fotoakselatör, } \\
\text { buti hidroksil tolun (BHT), etil-4- } \\
\text { dimetilaminobenzat ile silanize } \\
\text { edilmiş stronsiyum aluminyum, } \\
\text { sodyum florur fosfat, silikat cam. } \\
\end{array}$ & $\% 86$ & 060700108 \\
\hline $\begin{array}{c}\text { Prime Bond } \\
\text { NT (Adeziv } \\
\text { sistem) }\end{array}$ & $\begin{array}{l}\text { Dentsply } \\
\text { Konstan } \\
\text { Almanya }\end{array}$ & $\begin{array}{c}\text { Di ve trimetakrilat resinler, } \\
\text { fonksiyonel amorf silika, PENTA, } \\
\text { cetylamine hidroflorid, aseton, } \\
\text { fotoinitiatör. }\end{array}$ & & 990928 \\
\hline
\end{tabular}

Tablo 7 Modifiye USPHS kriterleri

\begin{tabular}{|l|l|}
\hline Kriter & Skorlama \\
\hline Retansiyon & $\begin{array}{l}\text { Alfa: Restorasyonda herhangi bir kayıp yok } \\
\text { Charlie: Restorasyon tamamen ya da kısmen kaybedilmiş }\end{array}$ \\
\hline Renk & $\begin{array}{l}\text { Alfa: Restorasyonla diş dokusu arasında renk ve translüsensi } \\
\text { açısından uyumsuzluk yok } \\
\text { Bravo: Restorasyonun rengi klinik olarak kabul edilebilir } \\
\text { durumda } \\
\text { Charlie: Restorasyon diş rengiyle tamamen uyumsuz }\end{array}$ \\
\hline $\begin{array}{l}\text { Kenar } \\
\text { Renklenmesi }\end{array}$ & $\begin{array}{l}\text { Alfa: Restorasyon sınırlarında herhangi bir renklenme yok } \\
\text { Bravo: Restorasyon sınırlarında marjin boyunca penetre } \\
\text { olmayan renklenme var } \\
\text { Charlie: Restorasyon sınırlarında pulpal yönde dentin dokusuna } \\
\text { kadar inen renklenme var }\end{array}$ \\
\hline Kenar & $\begin{array}{l}\text { Alfa: Restorasyon sınırlarında sondla hissedilen ya da gözle } \\
\text { görülebilen bir aralanma yok } \\
\text { Restorasyon sınırlarında sondla hissedilen ve gözle görülebilen } \\
\text { bir aralanma var } \\
\text { sınırlarında dentin dokusunu içeren açıklık var }\end{array}$ \\
\hline $\begin{array}{l}\text { Sekonder } \text { Restorasyon } \\
\text { cürük }\end{array}$ & $\begin{array}{l}\text { Alfa: Restorasyon sınırlarında herhangi bir çürük başlangıcı } \\
\text { gözlenmiyor } \\
\text { Charlie: Restorasyon sınırlarında çürük gözleniyor }\end{array}$ \\
\hline $\begin{array}{l}\text { Yüzey } \\
\text { Yapısı }\end{array}$ & $\begin{array}{l}\text { Alfa: Sondla muayene edildiğinde restorasyon yüzeyi ile çevre } \\
\text { mine dokusu aynı özelliklere sahip Bravo: Restorasyonun yüzeyi } \\
\text { çevre mine dokusuna göre pürüzlülük göstermektedir. Charlie: } \\
\text { Restorasyon yüzeyi tamamen bozulmaya uğramış durumdadır. }\end{array}$ \\
\hline Anatomik & $\begin{array}{l}\text { Alfa: Restorasyonun sınırları dişin anatomik formuna uygun } \\
\text { Bravo: Restorasyonun sınılları dişin anatomik formuna uygun } \\
\text { değil fakat dentin dokusu açığa çıkmamış } \\
\text { Charlie: Dentin dokusunun açığa çıktığı anatomik form kaybı }\end{array}$ \\
\hline $\begin{array}{l}\text { Postoperatif } \\
\text { Hassasiyet }\end{array}$ & $\begin{array}{l}\text { Alfa: Hassasiyet yok } \\
\text { Bravo: Hassasiyet var ama katlanılabilir (restorasyonun } \\
\text { yenilenmesine gerek yok) } \\
\text { Charlie: Hassasiyet var ve katlanılamaz düzeyde (restorasyonun } \\
\text { yenilenmesine gerek var) }\end{array}$ \\
\hline
\end{tabular}




\section{BULGULAR}

Çalışmamıza katılan yaş ortalaması 25.5 olan hastaların tümü 6. ayda kontrol randevularına geldi. 12. ay kontrollerinde 1 hasta, 18 . ayda 2 hasta, 24. ayda ise 2 hasta eksiği ile birey sayısı 38'e, toplam restorasyon sayısı ise 316'ya düştü. Değerlendirilen tüm restorasyonlar tablo 8'de gösterilmektedir.
Ayrıca her materyalin kendi içinde zamana bağlı olarak yüzey yapısındaki değişiklik istatistiksel olarak anlamlı değildi ( $p>0.05)$.

Restorasyonlar uygulandıktan 1 hafta sonra yapılan klinik değerlendirmelerde post operatif hassasiyet açısından 12 Quixfil, 13 Surefil SDR flow restorasyonu bravo skoru aldı. Bu verilere göre hassasiyet açısından restoratif materyaller arasında istatistiksel olarak anlamlı bir fark bulunmadı $(p>0.05)$. 6. ayda ise 2

Tablo 8. Restorasyonların modifiye USPHS kriterlerine göre değerlendirilme sonuçları

\begin{tabular}{|c|c|c|c|c|c|c|c|c|c|c|c|c|c|c|c|c|c|c|c|c|c|c|c|c|c|c|c|c|c|c|}
\hline & \multicolumn{15}{|c|}{ QUIXFIL POSIER IOR } & \multicolumn{15}{|c|}{ SUREFIL SDR FLOW } \\
\hline & \multicolumn{3}{|c|}{0} & \multicolumn{3}{|c|}{6} & \multicolumn{3}{|c|}{12} & \multicolumn{3}{|c|}{18} & \multicolumn{3}{|c|}{24} & \multicolumn{3}{|c|}{0} & \multicolumn{3}{|c|}{6} & \multicolumn{3}{|c|}{12} & \multicolumn{3}{|c|}{18} & \multicolumn{3}{|c|}{24} \\
\hline & n & A & в & $n$ & A & в & n & A & B & $\mathbf{n}$ & A & B & n & A & B & n & A & в & $n$ & A & в & n & A & в & n & A & B & n & A & B \\
\hline RETANSIYON & 178 & 178 & 0 & 17 & 178 & 0 & 178 & 178 & o & 178 & 178 & 0 & 178 & 178 & o & 178 & 178 & 0 & 178 & 178 & 0 & 178 & 178 & 0 & 178 & 178 & 0 & 178 & 178 & o \\
\hline RENK UYUMU & 178 & 178 & o & 17 & 178 & 0 & 174 & 172 & 2 & 166 & 164 & 2 & 158 & 156 & 2 & 178 & 178 & 0 & 178 & 178 & 0 & 174 & 171 & 3 & 166 & 163 & 3 & 158 & 155 & 3 \\
\hline $\begin{array}{c}\text { KENAR } \\
\text { RENKLENMESİ }\end{array}$ & 178 & 178 & 0 & $\begin{array}{c}17 \\
8\end{array}$ & 178 & o & 174 & 170 & 4 & 166 & 160 & 6 & 158 & 151 & 7 & 178 & 178 & 0 & 178 & 178 & o & 174 & 169 & 5 & 166 & 159 & 7 & 158 & 150 & 8 \\
\hline KENAR UYUMU & 178 & 178 & 0 & 17 & 178 & 0 & 174 & 169 & 5 & 166 & 160 & 6 & 158 & 152 & 6 & 178 & 178 & 0 & 178 & 178 & 0 & 174 & 167 & 7 & 166 & 158 & 8 & 158 & 150 & 8 \\
\hline $\begin{array}{l}\text { SEKONDER } \\
\text { QURÜUK }\end{array}$ & 178 & 178 & 0 & $\begin{array}{c}17 \\
8 \\
\end{array}$ & 178 & 0 & 178 & 178 & 0 & 178 & 178 & 0 & 178 & 178 & 0 & 178 & 178 & 0 & 178 & 178 & 0 & 178 & 178 & 0 & 178 & 178 & 0 & 178 & 178 & 0 \\
\hline YÜZEY YAPISI & 178 & 178 & 0 & 17 & 178 & o & 174 & 174 & 0 & 166 & 164 & 2 & 158 & 156 & 2 & 178 & 178 & o & 178 & 178 & 0 & 174 & 174 & 0 & 166 & 164 & 2 & 158 & 156 & 2 \\
\hline $\begin{array}{l}\text { ANATOMIK } \\
\text { FORM }\end{array}$ & 178 & 178 & 0 & $\begin{array}{c}17 \\
8\end{array}$ & 178 & 0 & 174 & 170 & 4 & 166 & 161 & 5 & 158 & 152 & 6 & 178 & 178 & 0 & 178 & 178 & 0 & 174 & 171 & 3 & 166 & 162 & 4 & 158 & 153 & 5 \\
\hline HASSASIYVET & 178 & 166 & 12 & 17 & 176 & 2 & 174 & 174 & 0 & 166 & 166 & 0 & 158 & 158 & 0 & 178 & 165 & 13 & 178 & 177 & 1 & 174 & 174 & 0 & 166 & 166 & 0 & 158 & 158 & o \\
\hline
\end{tabular}

Çalışmamızda, 24 aylık sürenin sonuna kadar Quixfil ve Surefil SDR Flow restorasyonlarından hiçbiri charlie skoru almadı. Retansiyon oranı \%100'dür.

Restorasyonlar uygulandıktan 1 hafta sonra (başlangıç) ve 6 . ayda yapılan klinik değerlendirmelerde renk uyumu, kenar renklenmesi, kenar uyumu, anatomik formda değişiklik gözlenmedi. Tüm restorasyonlar alfa skoru aldı. 12, 18 ve 24 . aylarda renk uyumu açısından restoratif materyaller arasında istatistiksel olarak anlamlı bir fark bulunmadı ( $p>0.05$ ). Ancak her materyalin kendi içinde zamana bağlı olarak renk uyumundaki değişiklik istatistiksel olarak anlamlı değilken, kenar renklenmesi, kenar uyumu ve anatomik formdaki değişiklik anlamlıydı $(p<0.01)$.

Çalışmamızda, 24 ayın sonunda her iki kompozit grubunda da sekonder çürük görülmemiştir. Tüm restorasyonlar alfa skoru almıştır.

Restorasyonlar uygulandıktan 1 hafta sonra (başlangıç) ve 6. ayda ve 12 . Ayda yapılan klinik değerlendirmelerde yüzey yapısında değişiklik gözlenmedi. Tüm restorasyonlar alfa skoru aldı. 18 ve 24. aylarda renk uyumu açısından restoratif materyaller arasında istatistiksel olarak anlamlı bir fark bulunmadı ( $p>0.05)$.
Quixfil, 1 Surefil SDR flow restorasyonu bravo skoru aldı. 6 ay verilere göre hassasiyet açısından restoratif materyaller arasında istatistiksel olarak anlamlı bir fark bulunmadı ( $p>0.05$ ). Ancak her materyalin kendi içinde zamana bağlı olarak 1.hafta ve 6 . ay arasındaki değişimi anlamlıydı ( $p<0.01$ ). Restorasyonların 12., 18. ve 24. aydaki değerlendirmelerinde tüm restorasyonlar alfa skoru aldı.

\section{TARTIŞMA}

Tüm bulgular incelendiğinde; çalışmamızda kullandığımız akışkan nanokompozitin 2yıllık klinik performansı kondanse edilebilen kompozitin klinik performansından farklı çıkmamıştır. Bu durumda hipotezimiz doğrulanmıştır.

Restoratif materyallerin özelliklerinin araştırılması genellikle in vitro çalışmalarla yapılmaktadır. Ancak ne kadar mükemmel şartlarda yapılsa da, ağız ortamındaki değişken parametrelerden dolayı materyalin klinik performansı tam olarak yansıtılamaz. Dental materyallerin çok hızı bir şekilde gelişmesi ve değişmesi, araştırmaların yürütülmesinde karşılaşılan güçlükler, sonuçlandırılmasının uzun sürmesi gibi sebeplerle literatürde klinik çalışmalara in vitro araştırmalara göre 
daha az rastlanılmaktadır. ${ }^{12-16}$ Tüm bu nedenlerden dolayı; araştırmamız 2 yıllık bir klinik takip çalışması olarak planlanmıştır.

Klinik çalışmaların sonuçları değerlendirilirken en çok üzerinde durulan konu restorasyonların retansiyonu yani tutuculuk özelliğidir. Bir restorasyonun ağızda fonksiyon gördügü süre, uygulanan materyal yada tekniğin başarısını gösteren en önemli kriter olarak değerlendirilmektedir. 6 aylık sürede restorasyonların retansiyon oranının \% 95 olarak bulunması ADA'nın restoratif materyalin klinik olarak kabul edilmesi için gerekli kriterlerinden birisidir. ${ }^{15}$ Birinci ve ikinci sınıf diş preperasyonlarına uygulanan 2 farklı kompozit rezinin 5 yıllık klinik takibinin yapıldığı bir araştırmada 2. yılın sonunda tüm restorasyonlar alfa ile skorlanırken, 5. yılın sonunda retansiyon oranının \%86 ve $\% 87$ olarak belirtilmiştir. Düşen restorasyonların ikinci sınıf kompozit rezinler olduğunu okluzal restorasyonların retansiyon oranının $\% 100$ olduğu rapor edilmiştir. ${ }^{16}$ Bizim çalışmamızda retansiyon oranı $\% 100$ bulunmuştur.

Kompozit rezinlerin renk uyumu diş ile arasındaki renk geçişinin belirsiz olması ile tanımlanabilir. ${ }^{16}$ Günümüzde kullanılan geleneksel ve hibrit kompozit rezinlerin diş rengi ile uyumu oldukça başarılıdır. Bu başarı yapılan klinik çalışmalarla da desteklenmektedir. 17,18 Ancak akışkan kompozitlerin ise renk seçenekleri fazla olmadığından, renk uyumu açısından sıkıntılar yaşanabilir. Ayrıca akışkan kompozitlerin yüksek organik matriks içeriği su emiliminin fazla olmasına ve restorasyonlarda zaman içinde renk değiş̧imi görülmesine neden olmaktadır. ${ }^{19,20}$ Karaman ve diğ. çürüksüz servikal lezyonlara uyguladıkları nanofil ve akışkan kompozitlerin 24 ay klinik takibini yapmışlar ve renk uyumu açısından akışkan kompozitlerin hepsinin alfa skoru aldığını vurgulamışlardır. ${ }^{21}$ Ancak ikinci sınıf kavite preparasyonlarının bir geleneksel ve bir akışkan kompozitle restore edildiği klinik takip çalışmasında ise renk uyumunun 12. aydan sonra önemli derecede düştüğü ve bu bozulmanın akışkan kompozit grubunda daha fazla olduğu belirtilmiştir. ${ }^{22}$ Çalışmamızda 6 . ayda her iki grup için tüm restorasyonlar alfa değeri almıştır. 12 . ay da renk uyumunda her iki grupta da artış gözlnemiş ancak 18 ve 24. aylarda renk uyumunda bir artış gözlenmemiştir. Hem Kompozit grupları arasında hem de her kompozit grubunun kendi içinde zaman dilimleri arasında değişim istatistiksel olarak anlamlı bulunmamıştır.

Kenar renklenmesi kompozit restorasyonlarda zaman içinde ortaya çıkan sorunlardan birirdir ve en önemli nedeni ise kenar sızıntısıdır. ${ }^{23}$ Kenar renklenmesine prepare edilmemiş mine yüzeyinde kalan kompozit fazlalıkları ile diş arasında oluşan renklenmenin neden olabileceğini belirtilmiştir. ${ }^{24}$ Farklı rezin kompozitlerin I. sınıf ve II. Sınıf kavitelerde 3 yıllık bir süreçte klinik takibinin yapıldığ bir araştırmada ise 6 . ve 12. ayda tüm restorasyonların kenar renklenmesi alfa skoru alırken, 3. yılın sonunda ise kenar renklenmesinde artış olduğunu fakat zamana bağlı değişimin istatistiksel olarak anlamlı olmadığını belirtmişlerdir. ${ }^{25}$ Çalışmamızda ise başlangıç ve 6 . ay kontrollerinde tüm restorasyonlar alfa skoru almış, kenar renklenmesi gözlenmemiştir. Zaman içinde 12., 18. ve 24. aylarda her iki kompozit grubunda da kenar renklenmesinde bir artış gözlenmiş ve bu artış istatistiksel olarak anlamlı bulunmuştur. Kenar renklenmesinden bravo ile skorlanan restorasyonların sayısına bakıldığında ise akışkan kompozit grubundaki bravo ile skorlanan kenar renklenmesi gösteren restorasyon sayısı kondanse edilebilen kompozit grubundan fazla olduğu görülmüştür. Ancak bu fark istatistiksel olarak anlamlı bulunmamıştır. Bu farkı akışkan kompozitin kaviteye tek seferde yerleştirilmesiyle oluşan polimerizasyon büzülmesi ve kaspal defleksiyon nedeniyle oluşan kenar aralanmasıyla ilişkilendirebiliriz.

Restorasyonların değiştirilme nedenleri arasında kenar uyumunun bozulması önemli bir yer tutmaktadır. 26 Sadeghi ve diğ. mikrohibrit, nanofil ve kondanse edilebilebilir kompozitlerin I. sınıf restorasyonlarda 18 aylık klinik takibini yapmışlar, kenar uyumu açısından gruplar arasında bir fark olmadığını rapor etmişlerdir. Buna bağlı olarak da günümüzde kullanılan kompozitlerin kenar renklenmesinin sebeplerinden biri olan polimerizasyon büzülmesinin doldurucu içeriğinden çok uygulayıcı farklıığından etkilenebileceğini de belirtmişlerdir. ${ }^{27}$ Araştırmamızda ise tüm restorasyonlar başlangıç ve 6. ayda alfa ile skorlanmıştır. Zaman içinde 12., 18. ve 24. aylarda hem Quixfil hem de Surefil SDR Flow grubunda kenar uyumunun bozulmasında bir artış gözlenmiş ve bu artış istatistiksel olarak anlamlı bulunmuştur. Kenar uyumundan bravo ile skorlanan restorasyonların sayısına bakıldığında ise akışkan kompozit grubunun kondanse edilebilen kompozit grubundan fazla bravo ile skorlandığı görülmüştür. Ancak bu fark istatistiksel olarak anlamlı bulunmamıştır.

Rezin esaslı restoratif materyalleri değerlendirirken bakılan parametrelerden birisi de sekonder çürük oluşumudur. Bizim çalışmamızda da iki yıllık izleme süresince hiçbir dişte sekonder çürüğe rastlanılmamıştır. Tüm restorasyonlar alfa ile skorlanmıştır. Bu 
başarıda; restorasyon yüzeylerinin mevcut pürüzsüzlüğüne bağlı olarak bakteri plağı akümülasyonuna imkan tanımamalarının yanında, hastaların mevcut ağız-diş sağlığının korunmasına yönelik hijyen alışkanlıkları konusunda yeterli düzeyde bilgi sahibi olmalarının da etkili olduğu düşünülmektedir. ${ }^{28}$

Araştırmamızda restorasyonların başlangıç, 6 . ay ve 12 . ay kontrollerinde tüm kompozitlerin yüzey yapısı alfa skoru almıştır. 18. ve 24. aylarda ise yüzey yapısı bravo ile skorlanan restorasyon sayısının Quixfil ve SDR Flow grubunda eşit sayıda olduğu görülmüştür. Dolayısıyla kompozitler arasında yüzey yapısı açısından bir fark çıkmamıştır. Çalışmamızda restorasyonların nerdeyse tamamının (24. ayın sonunda \%98.8) yüzey yapısı açısından alfa skoru alması; bitirme ve polisaj işlemlerinin doğru ve etkili bir şekilde yapıldığının göstergesi olabilir. Bu bulgular; başarılı bir bitirme, polisajın; yüzey yapısını ve de dolayısıyla restorasyonun klinik kullanım süresini, kenar uyumunu ve estetiğini etkileyeceğini bildiren çalışmaları da desteklemektedir. ${ }^{29-33}$

Bizim çalışmamızda baseline ve 6 . ay kontrollerinde hiç aşınma gözlenmemiştir. 12., 18. ve 24. aylarda aşınma gözlenmiş ve zaman bağlı olarak da sayıca artmıştır. Restorasyon grupları karşılaştırıldığında ise akışkan kompozitlerin aşınmaya karşı dirençlerinin az olduğu görüşünün aksine Quixfil grubunun bravo ile skorlanan restorasyon sayısı Surefil SDR Flow grubundan daha fazla olduğu görülmüştür. Ancak bu fark da istatistiksel olarak anlamlı bulunmamıştır. Her kompozitin kendi içinde aşınan restorasyon sayısının zamanla arttığı belirlenmiş ve bu artış da istatistiksel olarak anlamlı bulunmuştur. Celik ve diğ. okluzal ve ara yüz çürüklerine uyguladıkları Quixfil ve Grandio rezin kompozitlerin 2 yıllık klinik takibini yapmışlar. Tüm restorasyonların anatomik form açısından alfa ile skorlandığını bildirmişlerdir. ${ }^{34}$ Günümüzde kullanılan kompozit rezinler, fiziksel ve mekanik özellikler açısından güçlendirilmiş oldukları için iki yıl gibi kısa sürelerde gözle görülür miktarda aşınmaya uğramamaktadırlar. Bu nedenle, gözün algılama sınırlarının dışında kalan mikro düzeyde olan aşınmaların ölçülmesi için daha ayrıntılı yöntemler kullanılması gerektiğini düşünmekteyiz.

Rezin esaslı restoratif materyallerde postoperatif hassasiyetin olmasının nedeni genellikle materyaldeki polimerizasyon büzülmesine ve/veya uygulanan yanlış klinik prosedürlerlere bağlanmaktadır. Ancak bununla beraber, postoperatif ağrının hastaya sözel olarak sorularak belirlendiği ve bunun için subjektif ce- vaplar alındığı belirtilmiştir. ${ }^{35,36}$ Ağrı eşiğinin kişiden kişiye değişmesi, yapılan restoratif uygulamalarının farklıığı, uygulayıcılar arası değişim de bu kriterin değerlendirilmesinde standardizasyonun sağlanama- masına sebep olur. Arka dişlerde yapılmış olan kom-pozit rezin restorasyonların klinik performanslarının değerlendirildiği takip çalışmalarında; postoperatif hassasiyetin çok düşük bir oranda (<\%5) gözlendiği ve bu durumun geçici olduğu pek çok araştırmada bildirilmiştir. ${ }^{36-}$ ${ }^{40}$ Çalışmamızda ise bir hafta sonraki başlangıç kontrol randevusunda; 12 Quixfil, 13 SDR Flow restorasyon bravo ile skorlandı. 6. ayda sadece 2 Quixfil ve 1 SDR Flow restorasyon bravo ile skorlanırken, 12, 18 ve 24 . aylarda ise hiç hassasiyet gözlenmemiştir. Hassasiyet açısından kompozit grupları arasında fark çıkmamıştır. Ancak zaman dilimleri arasında her kompozit grubunun başlangıç ve diğer aylar arasındaki değişim anlamlı bulunmuştur. Ancak 6, 12, 18 ve 24 aylar arasındaki değişim anlamlı değildir. Başlangıçta gözlenen hassasiyetin materyalin polimerizasyon büzülmesi ya da yapısından kaynakla- nabileceği gibi, diş preperasyonu, asit uygulaması, bitirme ve polisaj işlemleri sırasında ki olası irritasyonlara da bağlı olabileceği düşünülmektedir. Daha sonraki zamanlarda hassasiyet görülmemesi her iki mater- yalin de beklenildiği gibi klinik başarısının yüksek olmasına bağlanabilir.

Yaptığımız çalışmada iki yıl sonunda, restorasyonlardan hiçbiri "Charlie" skoru almamış dolayısıyla yenilenmelerine gerek görülmemiştir. Bununla birlikte; başlangıç okluzal lezyonlarının tedavisinde kullanılan restoratif materyallerin başarısından söz etmek için iki yıldan daha uzun süreli klinik izleme sonuçlarına gerek vardır.

$\mathrm{Bu}$ araştırmada yer alan materyaller üzerinde çok sayıda in vitro çalışma yapılarak, bunların fiziksel ve mekanik özellikleri incelenmiş ancak bu sonuçlar az sayıda klinik çalışmalarlarla desteklenmiştir. Literatürde başlangıç okluzal çürüklerin tedavisinde kullanılan yeni geliştirilmiş nanofil akışkan kompozit rezinlerin ve kondanse edilebilen nanohibrit kompozitlerin aynı araştırmada kullanılıp takip edildiği klinik çalışma sayısı çok azdır. Yapmış olduğumuz klinik çalışma ile bu alandaki eksikliğin giderilmesine bir katkımız olacağı ve elde edilen sonuçların diş hekimliği literatürüne ışık tutacağı inancındayız.

\footnotetext{
Teşekkür

Yazarlar bu çalışmayla ilgili herhangi bir çıkar çatışmasını reddederler. Açıklama bildirimi:

Yazarlar tarafından herhangi bir potansiyel çıkar çatışması bildirilmemiştir.
} 


\section{KAYNAKLAR}

1. Kölüş $T$, Ülker H . Geçmişten günümüze çürük ve restoratif materyaller. Atatürk Üniv Diş Hek Fak Derg 2021; 31: 130-7.

2. Sutthavong S, Taebanpakul S, Kuruchitkosol C, Ayudhya TI, Chantveerawong,T, Fuangroong S, et al. Oral health status, dental caries risk factors of the children of public kindergarten and schools in Phranakornsriayudhya, Thailand. J Med Assoc Thai 2010; 93: S71-8.

3. Neuhaus KW, Rodrigues JA, Hug I, Stich H,Lussi A. Performance of laser fluorescence devices, visual and radiographic examination for the detection of occlusal caries in primary molars. Clin Oral Investig 2011; 15: 635-41.

4. Fleming GJ. Advances in dental materials. Prim Dent J 2014; 3:54-61.

5. Hayes, M., Allen, E., da Mata, C., McKenna, G.,Burke, F. Minimal intervention dentistry and older patients part 2: minimally invasive operative interventions. Dent Update 2014; 41: 500-2, 5045.

6. Attar N, Tam LE, McComb D. Flow, strength, stiffness and radiopacity of flowable resin composites. J Can Dent Assoc 2003; 69: 516-21.

7. Yapar İ, Çelik M, Sağsöz Ö, Karalar B, Seven N, Bayındır Y. Farklı polimerizasyon tekniklerinin kompozit rezinlerin mekanik ve fiziksel özelliklerine etkisi. Atatürk Üniv Diş Hek Fak Derg 2020; 30: 26-32.

8. Haugen HJ, Qasim SB, Matinlinna JP, Vallittu P, Nogueira LP. Nano-CT as tool for characterization of dental resin composites. Sci Rep 2020 Sep 23; $10: 15520$.

9. Shaalan OO, Abou-Auf E, El Zoghby. AF. Clinical Evaluation Of Flowabjle Resin Composite Versus Conventional Resin Composite İn Carious And Noncarious Lesions: Systematic Review And Meta-Analysis. J Conserv Dent 2017;20: 380-5

10. Gallo JR, Burgess JO, Ripps AH, Walker RS, Maltezos MB, Mercante DE.et all. Three-year clinical evaluation of two flowable composites. Quintessence Int 2010; 41:497-503.

11. Ekstrand KR, Ricketts DN, Kidd EA. Reproducibility and accuracy of three methods for assessment of demineralization depth of the occlusal surface: an in vitro examination. Caries Res. 1997; 31: 224-31.
12. Lussi A, Megert B, Longbottom C, Reich E, Francescut $P$. Clinical performance of a laser fluorescence device for detection of occlusal caries lesions. Eur J Oral Sci 2001; 109: 14-9.

13. Fagundes TC, Barata TJ, Carvalho CA, Franco, EB, van Dijken JW, Navarro MF. Clinical evaluation of two packable posterior composites: a five-year follow-up. J Am Dent Assoc 2009: 140: 447-54.

14. Geitel B, Kwiatkowski R, Zimmer S, Barthel CR, Roulet JF, Jahn KR. Clinically controlled study on the quality of class III, IV and V composite restorations after two years. J Adhes Dent 2004; 6: 247-53.

15. Ada. Acceptance program guidelines resin based compoistes for poasterior restorations american dental association council on scientific affairs. 2001

16. Fagundes TC, Barata TJ, Carvalho CA, Franco EB, van Dijken JW, Navarro MF. Clinical evaluation of two packable posterior composites: a five-year follow-up. J Am Dent Assoc. 2009; 140: 447-54.

17. Folwaczny M, Loher C, Mehl A, Kunzelmann $\mathrm{KH}$, Hinkel R. Tooth-colored filling materials for the restoration of cervical lesions: a 24-month followup study. Oper Dent 2000; 25: 251-8.

18. Brackett WW, Dib A, Brackett MG, Reyes AA, Estrada BE. Two-year clinical performance of Class $\mathrm{V}$ resin-modified glass-lonomer and resin composite restorations. Oper Dent. 2003; 28: 47781.

19. Musanje L, Shu M, Darvell BW. Water sorption and mechanical behaviour of cosmetic direct restorative materials in artificial saliva. Dent Mater. 2001; 17: 394-401.

20. Arai $Y$, Kurokawa $H$, Takamizawa T, Tsujimoto A, Saegusa M, Yokoyama M, Miyazaki M. Evaluation of structural coloration of experimental flowable resin composites. J Esthet Restor Dent 2021; 33: 284-93.

21. Karaman E, Yazici AR, Ozgunaltay G, Dayangac B. Clinical evaluation of a nanohybrid and a flowable resin composite in non-carious cervical lesions: 24month results. J Adhes Dent 2012; 14: 485-92.

22. Rocha Gomes Torres C, Rego HM, Perote LC, Santos LF, Kamozaki MB, Gutierrez N.C. at all. A split-mouth randomized clinical trial of conventional and heavy flowable composites in class II restorations. J Dent 2014; 42: 793-9.

23. Estafan AM, Estafan D. Microleakage study of flowable composite resin systems. Compend Contin Educ Dent 2000; 21: 705-8, 710, 2; quiz 714.

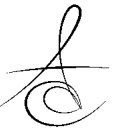


24. Turner EW, Shook LW,Owens BM. Microleakage of flowable composite resins when utilized as liners in Class II posterior composite resin restorations. J Tenn Dent Assoc. 2002; 82: 23-6.

25. Celik C, Arhun N,Yamanel K. Clinical evaluation of resin-based composites in posterior restorations: a 3-year study. Med Princ Pract 2014; 23: 453-9.

26. Attar N, Turgut MD,Gungor HC. The effect of flowable resin composites as gingival increments on the microleakage of posterior resin composites. Oper Dent 2004; 29: 162-7.

27. Sadeghi M, Lynch CD, Shahamat N. Eighteenmonth clinical evaluation of microhybrid, packable and nanofilled resin composites in Class I restorations. J Oral Rehabil 2010; 37: 532-7.

28. Kes G, Başeren M. Beyaz Nokta Lezyonları. Atatürk Üniv Diş Hek Fak Derg 2020; 30: 671-80.

29. Kameyama A, Nakazawa T, Haruyama A, Haruyama C, Hosaka $M$, Hirai $Y$. Influence of finishing/polishing procedures on the surface texture of two resin composites. Open Dent J 2008; 2: 56-60.

30. Sarac D, Sarac YS, Yuzbasioglu E, Bal S. The effects of porcelain polishing systems on the color and surface texture of feldspathic porcelain. J Prosthet Dent 2006; 96: 122-8.

31. Ono T, Ishikawa K, Yamaba O, Nokubi T. Effect of texture of polishing particle on the surface roughness of a cobalt-chromium alloy using a centrifugal shooting type polishing machine. Dent Mater J 2005; 24: 487-93.

32. Watanabe $T$, Miyazaki M, Moore BK. Influence of polishing instruments on the surface texture of resin composites. Quintessence Int 2006; 37: 61-7.

33. Braun KO, Mello JA, Rached RN, Del Bel Cury AA. Surface texture and some properties of acrylic resins submitted to chemical polishing. J Oral Rehabil.2003; 30: 91-8.

34. Celik C, Arhun N,Yamanel K. Clinical evaluation of resin-based composites in posterior restorations: 12-month results. Eur J Dent 2010; 4: 57-65.

35. Graunaite I, Skucaite N, Lodiene G, Agentiene I, Machiulskiene $V$. Effect Of resin-based and bioceramic root canal sealers on postoperative pain: A Split-Mouth Randomized Controlled Trial. J Endod 2018 May;44: 689-93.

36. Opdam NJ, Feilzer AJ, Roeters JJ, Smale I. Class I occlusal composite resin restorations: in vivo postoperative sensitivity, wall adaptation, and microleakage. Am J Dent 1998; 11: 229-34.
37. van Dijken JW, Pallesen U. A Randomized 10-year prospective follow-up of class II nanohybrid and conventional hybrid resin composite restorations. ] Adhes Dent 2014; 16: 585-92.

38. Van Landuyt K.L., Peumans, M., De Munck, J., Cardoso, MV, Ermis B, Van Meerbeek B. Threeyear clinical performance of a HEMA-free one-step self-etch adhesive in non-carious cervical lesions. Eur J Oral Sci 2011; 119: 511-6.

39. Kramer N, Reinelt C, Richter G, Petschelt A, Frankenberger R. Nanohybrid vs. fine hybrid composite in Class II cavities: clinical results and margin analysis after four years. Dent Mater 2009; 25: 750-9.

40. Manhart J, Chen HY, Mehl A, Hickel R. Clinical study of indirect composite resin inlays in posterior stress-bearing preparations placed by dental students: results after 6 months and 1, 2, and 3 years. Quintessence Int 2010; 41: 399-410.

\author{
Sorumlu Yazarın Yazışma Adresi \\ Dr. Dt. Aslı BERBER \\ Gölcük Ağız ve Diş Sağlığı Merkezi \\ Şehitler mah. Atatürk bulvarı no:156 \\ Gölcük Kocaeli \\ E-mail: klsasli@gmail.com
}

